\title{
UM CASAMENTO FELIZ: \\ DIREITO INTERNACIONAL E SOCIEDADE CIVIL GLOBAL NA FORMAÇÃO DOS REGIMES INTERNACIONAIS ${ }^{1}$
}

\author{
Ana Paula Tostes
}

\begin{abstract}
RESUMO
O artigo tem o objetivo de demonstrar a relação entre o aumento da sociedade civil global e o Direito internacional público, por um lado e, por outro, a importância dos regimes internacionais para a perspectiva da participação de atores não-estatais nas relações internacionais. O debate na literatura sobre regimes internacionais aponta para a necessidade de realizarem-se mais pesquisas empíricas sobre os condicionantes do sucesso dos regimes internacionais, porém já é possivel destacar evidências a respeito de um importante papel que vem sendo ocupado por atores não-soberanos na formação de regimes: o papel de especialistas. $O$ artigo é uma reflexão sobre o conceito de "regime internacional" e seus limites e apresenta uma nota preliminar de pesquisa sobre as possibilidades da influência de atores da sociedade civil na busca da formação de um regime internacional de meio ambiente, com destaque na participação do Brasil no processo de formulação de um regime de biosseguranca.
\end{abstract}

PALAVRAS-CHAVE: regimes internacionais; Direito Internacional; meio ambiente; sociedade civil global.

\section{INTRODUÇÃO}

A Conferência das Nações Unidas sobre Meio Ambiente e Desenvolvimento (Unced), ocorrida no Rio de Janeiro de 3 a 14 de junho de 1992, é o marco para a aceleração da feitura de acordos internacionais sobre o meio ambiente e para o aparecimento dos Fóruns paralelos às Conferências Internacionais em que só os Estados têm representação. A reunião ficou conhecida como Rio-92 e foi a primeira reunião internacional de magnitude a realizar-se após o fím da Guerra Fria, contando com a participação de delegações de 175 países no fórum oficial e cerca de 20000 pessoas no fórum paralelo.

Não é objetivo deste artigo avaliar a efetividade da agenda da Rio-92 nem o sucesso ou fracasso das regras formais internacionais sobre o tema do meio ambiente associado ao desenvolvimento, mas,

\footnotetext{
1 Este artigo é a versão preliminar do trabalho intitulado Why Do Civil Organizations Matter to International Regimes?, apresentado na VIII International Conference of Brazilian Studies Association - BRASA, realizada na Vanderbilt University, Nashville, Tennessee, de 13 a 16 de outubro de 2006.
}

sim, identificar que se consolidam no começo da década de 1990 o princípio e o valor de que a preservação do planeta é um interesse social e não apenas estatal, e tem caráter universal. O reflexo deste princípio pode ser conferido na aceleração de iniciativas de acordos internacionais e proliferação de instituições internacionais e agrupamentos de setores da sociedade civil de alcance transnacional interessados na defesa do meio ambiente. Essa foi a base da fertilização de muitas mudanças no estabelecimento de negociações e nas pesquisas sobre desenvolvimento. Assim, uma nova concepção de política de meio ambiente começa a forjar-se em plena aceleração da globalização, bem como o debate sobre a emergência de uma sociedade civil global.

Será que o aumento de regras está associado ao aumento de interesse, diversidade de atores interessados e maior participação sobre um tema de caráter internacional? Se essa associação confirmar-se, que estratégia pode ser de grande utilidade para que atores não-estatais adquiram condições de influência nas relações internacionais?

Este artigo visa contribuir para o debate sobre o papel instrumental e estratégico das instituições na luta pelo poder nas relações internacionais. Em 
outras palavras, se não são apenas regras formais e embates frontais que contam nas relações internacionais, os regimes internacionais importam na competição internacional e os atores não-estatais importam nos regimes internacionais. Isso não significa, no entanto, que os Estados nacionais estejam ponderando seu modo de competição internacional por poder, mas, sim, que novos instrumentos de pressão e dominação passaram a ser cada vez mais importantes em um mundo pósguerra em que comunicação, conhecimento, ciência e informação são cada vez mais valorizadas.

Os regimes internacionais têm exercido um papel cada vez mais complexo e abrangente sobre diversas áreas de cooperação e conflito nas relações internacionais, no campo dos direitos humanos e da justiça, por exemplo. Sem dúvida, o tema do meio ambiente facilita uma reflexão preliminar sobre a relação entre o aumento do poder de influência de atores não-estatais no aumento da busca de regulação internacional, mas, por outro lado, também é capaz de revelar as dificuldades da substituição da luta por poder pelo diálogo racional ou científico entre grandes potências internacionais. Nesse cenário aparentemente infértil é que propomos que os atores não-estatais podem vir a ocupar gradualmente um espaço de influência nas relações internacionais.

Diante desse quadro de reflexões sobre a relação entre institucionalização e aumento da participação de atores não-estatais nos debates e decisões internacionais, este artigo está organizado da seguinte forma: primeiro apresentarei a literatura que vem mapeando a sociedade civil global e consolidando a interpretação basilar da relação entre Direito Internacional e atores não-estatais; na segunda seção discutirei por que os regimes importam e a relação entre atores não-estatais e regimes internacionais; em terceiro lugar, ilustrarei o debate teórico da relação entre o direito internacional, sociedade civil e regimes internacionais com o caso do meio ambiente. Observe-se que, apesar de não ser um regime bem sucedido, sua escolha para esse artigo é absolutamente adequada aos argumentos principais de que os atores não-estatais, representantes da sociedade civil, ainda têm um longo caminho a percorrer, mas já visualizaram que o caminho vem sendo asfaltado pelo Direito internacional. Finalmente, uma vez conduzidos os argumentos para a reflexão sobre que papel os atores não-estatais podem exercer na pressão de forças internacionais, concluo que se estes não possuem representação soberana nem forças armadas podem ser indispensáveis pela especialização e capacidade de concentração de informação e conhecimento. Isto porque a expertise temática está sendo buscada, cada vez mais, fora dos Estados e a via de influência dos atores não-estatais já está clara no principal papel assumido pelas organizações não-governamentais em suas participações em organizações internacionais e conferências: o papel de especialistas.

\section{REGULAÇÃO INTERNACIONAL E SOCIE- DADE CIVIL GLOBAL}

Segundo pesquisadores que vêm trabalhando com o mapeamento da "sociedade civil global"2, tais como Kaldor, Anheier, Stares e Glasius, do Center for Global Civil Society and Centre for the Study of Global Governance (da London School of Economics and Political Science), o crescimento do número de tratados concluídos e ratificados precede o crescimento de atores da sociedade civil que agem em redes transnacionais. Especialmente a década de 1990 representou um marco único no crescimento de tratados internacionais, sendo que, nesse período, quase dobrou o número de tratados ratificados por países sobre os mais diversos assuntos (cf. gráficos Record, $8 \mathrm{~b} ; 8 \mathrm{c}$ (GLASIUS, KALDOR \& ANHEIER, 2002, p. 291)).

Anheier, Glasius e Kaldor (2001), ao pesquisarem a sociedade civil global, sugerem que esta surge de dois fatos complexos: a globalização econômica (produção, finanças, mercado etc.) e o Direito internacional (ratificação de tratados e regras internacionais, especialmente na área de direitos humanos). Assim, se a ação transnacional de atores não-estatais, grupos e associações civis de alcance internacional e organizações não-governamentais, dependem da institucionalização internacional, por outro lado, a atual realidade do ambiente internacional combina a crescente institucionalização com o crescente povoamento de atores da sociedade civil.

\footnotetext{
2 Esse conceito não será questionado neste artigo, mas, sim, considerado em sua referência mínima à existência de uma participação de setores de sociedades civis nacionais em fóruns internacionais por meio de representações nãoestatais ou como ativistas em networks transnacionais.
} 
Keck e Sikkink (1998) pesquisam a metodologia das transnational advocacy networks, que se caracterizam por usar a informação, valores, identidades e crenças comuns para motivar ações políticas e para ganhar apoio de instituições poderosas em defesa de seus princípios. Assim as autoras desenvolveram mecanismos formais para identificar, mapear e explorar os atributos das networks, sua formação e a sustentação interna de seus membros. As Advocacy Networks transformam-se em estruturas de poder, segundo as autoras, sempre que o esquecimento ou a supressão de informação são sustentações de abuso de poder e violência. Não se trata de um fenômeno novo, mas a articulação de atores individuais e grupos através de networks ganha, naturalmente, melhores condições de efetividade e importância com a globalização, que marca o aumento de organizações não-governamentais (ONGs) internacionais, facilidades tecnológicas de comunicação, transporte e circulação de informação ${ }^{3}$.

Neste contexto, a idéia de que há uma "cultura global" exerce um papel-chave na constituição das características a serem observadas nos novos fenômenos globais. Mas não deve ser confundida com a idéia de que há uma nova arena de consenso que leva a uma interpretação do conceito de sociedade civil global enquanto um reflexo de uma sociedade única global ou de um sistema mundial. Como está dito acima e, da mesma forma como argumentam Keck e Sikkink (1998), o que há no mundo interdependente contemporâneo é a emergência de uma sociedade civil que interage em uma fragmentada arena de disputas no campo das relações internacionais. Por isso as autoras preferem a designação 'sociedade civil transnacional' à de sociedade civil global ${ }^{4}$.

Segundo Keck e Sikkink, há um certo padrão estrutural mínimo a ser estudado: temáticas dife-

\footnotetext{
3 Keck e Sikkink (1998, p. 25ss.) classificam estágios de influência das networks: i) colocação de temas em agendas; ii) influência nos discursos (Estados e OIs); iii) influência em procedimentos institucionais (participação das ONGs, por exemplo); iv) influência sobre mudanças políticas em atores-chave (Estado, OIs, corporações etc.); v) influência no comportamento do Estado.

4 Uma das principais formas de influência na política governamental pela via das networks dá-se pelo que Keck e Sikkink (1998) designam como "efeito bumerangue", que impõe mudança de normas domésticas em função da pressão internacional causada pela ação de atores não-estatais
}

rentes apresentam um encaminhamento, pelas redes, muito semelhante, tais como: i) a centralidade de valores e idéias primárias; ii) a crença de que indivíduos fazem diferença; iii) o acesso criativo da informação; iv) emprego de atores não-governamentais ou de estratégias políticas objetivando campanhas (KECK \& SIKKINK, 1998, p. 2). Mesmo seguindo este padrão mínimo, networks sobre meio ambiente diferem em importantes aspectos em relação a outras networks como, por exemplo, as de direitos humanos. Isto porque estas não são tão claramente baseadas em princípios irrefutáveis.

As transnational advocacy networks sobre meio ambiente têm características próprias, pois para além da natureza polêmica de sua base cognitiva, elas operam simultaneamente nos níveis local, nacional e internacional. Assim, as pesquisas sobre a ação das networks vêm avaliando seu impacto sobre a governança internacional na área de meio ambiente focalizando duas arenas em especial. De um lado são estudados os impactos das networks sobre os Estados (no âmbito internacional) e as organizações internacionais. De outro lado são estudadas as suas estratégias de ação na formação de lobbies e na influência na negociação de tratados e formação de regimes internacionais.

Como no caso da formação de networks sobre meio ambiente, uma maior diversidade de concepções éticas, avaliações cognitivas e visões de mundo geram disputas a respeito de fundamentos sobre posições ideológicas e científicas, os próprios ativistas transnacionais evocam princípios éticos e defendem direitos buscando fundamentar suas posições. Campanhas internacionais sobre meio ambiente fazem surgir dilemas sobre propriedade (publica ou privada) e soberania e conflitos domésticos confundem-se, muitas vezes, com conflitos internacionais. Todas estas características próprias das networks sobre meio ambiente refletem-se também nos impasses da formação de um regime internacional de meio

de alcance internacional. Isto porque as ações em rede maximizam influências que a sociedade civil não consegue exercer sobre o seu próprio governo em função de sua dinâmica. Além de penetrarem debates no âmbito da sociedade civil e das instituições, podem vir a transformar posições políticas, eventualmente procedimentos e comportamentos. 
ambiente. Os regimes internacionais, vistos como uma inteligibilidade mútua do comportamento dos atores internacionais com rotinas organizacionais, refletem facilidades e dificuldades de coordenação de valores e preferências que podem dar-se nos níveis nacionais e transnacionais.

\section{POR QUE REGIMES INTERNACIONAIS IMPORTAM?}

Os regimes internacionais, as instituições e procedimentos que se desenvolvem junto a eles, desempenham a função de reduzir os riscos e incertezas e de melhorar a qualidade e a quantidade de informação disponível aos participantes de uma ação coordenada, ou seja, qualquer ação que pode afetar ou ser afetada pela ação de outro. Quanto maior a quantidade de temas agregados em um regime internacional, maior a responsabilidade dos atores quanto ao cumprimento dos acordos estabelecidos no seu contexto. Pode concluir-se, como faz Keohane (1993), que, diante deste quadro de possibilidades, a comunicação é fundamental, bem como a informação crível. Há uma relação, portanto, de fato, entre comunicação, cooperação e desempenho.

O estudo de regimes internacionais é um caminho adequado para compreender-se a ordem internacional contemporânea, pois se o conflito pode ser a regra no sistema de Estados, modelos institucionalizados de cooperação precisam ser compreendidos. Keohane observa que os regimes podem ser vistos como uma anomalia aparente, do ponto de vista da teoria realista. Na verdade, os regimes estão no enfoque da tradição das teorias da escolha racional e podem ser definidos como "Conjuntos de princípios, normas, regras e procedimentos de tomada de decisão implícitos e explícitos, em torno dos quais divergem expectativas dos atores" em uma realidade de relações internacionais (KEOHANE, 1993).

Há um conceito restrito e outro amplo de regime internacional, segundo Keohane (1993). No sentido restrito, regime define-se por regras explícitas em geral acordadas por governos em conferências internacionais formais. O regime monetário internacional acordado em Bretton Woods (que entrou em vigor em 1958) caracteriza-se por regras explícitas que ordenam taxas de câmbio fixas e procedimentos de consulta nos casos de mudança de taxas de câmbio. Assim, cada negociação que se segue soma-se à lista de regras e, naturalmente, algumas regras decaem com o tem- po. No sentido amplo, uma definição mais elástica permite-nos centrar a atenção menos na institucionalização formal e no desenvolvimento de regras e mais nos modelos de comportamento cooperativo, regularizados na política mundial. Neste caso, considera-se a importância das regras implícitas, na medida em que estas guiam concretamente comportamentos.

O conceito de Keohane é complementar à idéia de que regimes internacionais funcionam como variáveis intervenientes que se colocam entre fatores causais e os comportamentos (outcomes) dos atores. Esta formulação, desenvolvida por Krasner (1989), faz surgir questões como: i) qual é a relação entre fatores causais como poder, interesse e valores, e os regimes?; ii) qual é a relação entre os regimes e seus outcomes e os comportamentos dos atores participantes? A primeira questão pode ser respondida diferentemente, segundo paradigmas e perspectivas teóricas diferentes das relações internacionais. A segunda questão, tão importante quanto a primeira, pode ser explorada por uma pergunta abrangente e instigante que vem sendo feita por todas as teorias de regimes: regimes fazem diferença? Por quê?

Keohane (1983) defende que o aumento da interdependência leva ao aumento de regimes e diferencia acordos de regimes pela caracterização ad hoc ou mais abrangente. Os acordos, em geral, são adequados quando a densidade do tema a ser regulado é baixa. Quando se dá o contrário, ou seja, quando um objetivo substancial pode incidir em uma variedade de acordos potenciais em uma área substancial, os procedimentos de negociação passam a ganhar maior densidade. Naturalmente, uma demanda de regimes internacionais maior propicia a existência de regimes mais extensos, dado que uma maior densidade implica em mais interdependência.

As potências econômicas têm capacidade para manter os regimes econômicos internacionais que lhes favorecem: podem prover mais benefícios para os que cooperam e coagir outros a aderir às regras, porque são as detentoras dos meios de punição e de premiação. Se isto está correto, a concentração de poder entre países leva à estabilidade, e a fragmentação leva à fragmentação. Se regimes facilitam acordos e previnem conflitos, é preciso verificar sua efetividade. Se este não é eficaz, como é possível determinar uma mudança de regime? 
Levando em conta o conceito de Keohane, os procedimentos de um regime devem ser consistentes com os seus princípios e normas, ou seja, com os valores e os comportamentos dos atores envolvidos. Uma mudança de procedimento pode assim ser considerada interna aos regimes, não implicando necessariamente uma mudança do regime. Considera-se um regime modificado, apenas quando são reformados ou substituídos seus princípios ou suas normas, que são suas bases constitutivas. Da mesma forma, para que desapareça um regime, os seus princípios devem ser superados ou o comportamento definido em termos de direitos e obrigações, diante do fato dos valores em questão já não existirem. Já o enfraquecimento de um regime pode dar-se pela incoerência entre os participantes ou inconsistência entre o regime e o comportamento dos atores (KRASNER, 1989, p. 187-189).

Regimes servem também como importantes veículos para aprendizagem na produção de convergência entre políticas estatais. Este papel dos regimes têm sido subestimado, segundo Haas (1989, p. 377), pela literatura teórica e pela pesquisa empírica nas relações internacionais. Estas tendem a focar duas questões relativas a regimes internacionais: ordem política e crescimento econômico, deixando, assim, de lado, o debate sobre a capacidade transformadora que os regimes têm. Além disso, em muitos casos, atores não-estatais - ativistas, networks, indivíduos, movimentos sociais e ONGs - exercem um importante papel na constituição dos regimes.

Haas (1989) destaca especialmente o fato de que alguns regimes surgem do compartilhamento de conhecimento por uma comunidade e não simplesmente de interesses de grupos transnacionais e domésticos. O papel da "comunidade epistêmica" na estabilização dos regimes internacionais é fundamental, pois quando os cientistas têm uma só interpretação e diagnóstico para um problema, essa convicção gera credibilidade, imitação e valor.

\section{MEIO AMBIENTE: INFORMAÇÃO E PO- DER}

Em um contexto de progressivo aumento do Direito internacional é preciso identificar quais são as condicionantes que contribuem para que certas áreas de conflito de interesses sejam mais propícias a uma regulação internacional ampla e contínua. Young (1989a) já fez importantes esforços para responder a esta pergunta e identificar os determinantes do sucesso na barganha internacional. Para Young, nem o modelo utilitarista que foca o comportamento racional dos atores (neoinstitucionalistas), nem o modelo dos teóricos do poder (realistas e neo-realistas), são capazes de explicar por que alguns regimes prosperam e outros não. Assim, é preciso pesquisar-se mais sobre os regimes e desenvolver um novo modelo para ilustrar os fatores envolvidos nos sucessos e fracassos, bem como para compreendermos os limites e possibilidades dos atores não-estatais participarem do sucesso ou fracasso dos regimes.

Naturalmente, grandes potências preferem não debater sobre suas preferências ou tampouco se dispõem a compartilhar o poder de tomada de decisão sobre sua política externa. Entretanto, em algumas áreas, como a do meio ambiente, já sabemos que o debate e a pressão de grupos de interesses e setores da sociedade civil levaram a uma revisão sobre o âmbito de atuação e a esfera de pertencimento do poder sobre o destino de bens considerados da humanidade. Essa mudança de perspectiva sobre "o pertencimento" do meio ambiente e sobre a idéia de patrimônio comum da humanidade, logo, sobre a responsabilidade de sua defesa, traz uma quebra de legitimidade sobre qualquer argumento de poder e tem levado grandes potências ao diálogo ou ao respeito a direitos mínimos. Ainda que restrito e insuficiente quanto aos outcomes políticos no contexto das relações internacionais, a persuasão através de argumentos científicos e da detenção da informação ou da tecnologia torna-se um instrumento de ação, resistência e renitência.

Estudos sobre o papel da informação científica na formação dos acordos e políticas internacionais, ou do conhecimento derivado da pesquisa científica na condução da ação coletiva em matéria de meio ambiente, ressaltam a necessidade do debate sobre a relação entre conhecimento, interesse e poder na política internacional (ANDRESEN \& ØSTRENG, 1989; JASANOFF, 1990; HAAS, 1992; LITFIN, 1994; 1995; ANDRESEN et alii, 2000; PARSON, 2003).

Uma proeminente pesquisa de Young e Osherenko (1993) testou as várias escolas teóricas sobre regimes em cinco casos empíricos e concluiu que nenhuma delas é capaz de explicar sozinha todos os casos de formação de regimes. Ao mesmo tempo, os instrumentos teóricos são complementares para a explicação dos outcomes. 
Enfim, apesar de crescente, os estudos que exploram a relação entre ciência e política na arena internacional ainda não chegaram a conclusões completamente coerentes. Em muitos dos casos analisados tem-se verificado que a informação e o conhecimento científico são levados em conta nos debates e acordos internacionais, mas que, ao final do processo de tomada de decisão, estes não são os principais determinantes dos outcomes (DIMITROV, 2006, p. 27-41).

Se o conhecimento científico não determina a ação coletiva internacional, por outro lado, uma vez constituídos, de uma forma ou de outra, os regimes podem ainda ser vistos como veículos de transmissão de conhecimento e valor no ambiente internacional (YOUNG, 1989a), por terem a capacidade de serem usados para divulgação de informação e influência na convergência de políticas $^{5}$. Se regimes internacionais são conjuntos de regras formais e informais, e têm capacidade de transmissão e veiculação de conhecimento, a compreensão dos regimes não se reduz à manifestação das vontades e conflitos de interesses entre coletividades estatais, mas também à participação de outros grupos de interesse.

Partindo-se de duas hipóteses amplamente debatidas pela literatura, ou seja, que a institucionalização internacional é irreversível e que o tema do meio ambiente é um tema adequado para a verificação da intensificação do processo de institucionalização internacional, desenvolverei nesta seção argumentos sobre o fato de que regimes internacionais e instituições em geral são instrumentos de competição, exercício de pressão e influência - seja pelo uso do poder ou da informação. Isto porque não são interpretados aqui como fruto de convergência de interesses, mas na maioria das vezes como fruto de uma coordenação racional de interesses em conflito. Assim, regimes e instituições são instrumentos estrategicamente eficientes tanto para a ampliação do exercício de poder dos Estados quanto para a busca pela ampliação do poder de influência efetiva de atores não-estatais na competição internacional de idéias, valores e regras.

5 Um bom exemplo dado por Young (1989a) é o regime para controle da poluição marinha no Mar Mediterrâneo, surgido do Plano de Ação do Mediterrâneo, na década de 1970.
A irreversibilidade da institucionalização internacional está associada à irreversibilidade do processo de globalização (NYE, 2002), ou seja, nada garante uma coordenação de interesses, mas a interdependência leva à busca de regras mínimas e instituições. Neste contexto de reconhecida interdependência crescente, o tema do meio ambiente tornou-se paradigmático por naturalmente sempre ter sido tratado em sua particularidade transnacional. Atualmente, todo debate a seu respeito vem levando à reflexão sobre uma convergência de questões econômicas, sociais, culturais e políticas que não mais se dissecam e nem se resolvem em espaços territoriais delimitados por uma nação ou por uma burocracia política.

\section{IV.1. Global Environment Politics e regimes}

Apesar de o tema do meio ambiente não ser o limite, sem dúvida este ainda é o principal exemplo da ação e desenvolvimento de regimes internacionais que nos leva, necessariamente, a reconhecer tendências diferentes de abordar-se o papel das instituições internacionais, do direito internacional público e dos atores não-estatais nas relações internacionais.

Uma nova área de pesquisa que veicula o tema do meio ambiente a debates acerca de uma política global de meio ambiente, visto como Global Environment Politics (GEP), surgiu na defesa da idéia de que não há mais a possibilidade de uma abordagem efetiva sobre meio ambiente sem a consideração das conexões globais e do processo de interdependência. $\mathrm{Na}$ verdade, os novos enfoques de pesquisa sobre meio ambiente (GEP) relacionam mais fortemente o local-global quando reconhecem que as implicações sobre a regulação do meio ambiente são transversais e devem ser consideradas na sua interdisciplinaridade, incluindo aspectos históri$\cos$, geográficos, sociológicos, éticos, econômicos, de ciência e tecnologia além de interesses de políticas públicas, ciência política e relações internacionais. Assim, as mudanças do meio ambiente e as relações entre forças políticas globais devem incluir o papel dos Estados, dos atores multilaterais, do direito internacional, do sistema financeiro internacional, das corporações, dos movimentos sociais de caráter transnacional, das organizações não governamentais de alcance internacional, do desenvolvimento tecnológico e da ciência. Podemos verificar que neste novo contexto de valorização do debate sobre meio ambi- 
ente, sendo os regimes internacionais um conjunto de regras formais e informais, aos regimes não importam apenas manifestações de vontades e conflitos de interesses entre coletividades estatais, mas também de grupos de interesses, já que a definição de regimes abarca princípios (crenças, valores etc.) e normas (padrões de comportamento definidos em termos de direitos e obrigações), bem como regras e procedimentos de tomada de decisão.

\section{IV.2. Biosseguranca e regime internacional}

Dentre as questões mais discutidas atualmente sobre ambientalismo podemos destacar os temas da biodiversidade e da biossegurança, que envolvem debates sobre manutenção de ecossistemas, sobrevivência de espécies de plantas e animais, saúde, ciência e tecnologia na área da engenharia genética e ética. São conceitos em formação e em transformação; não se tratam de temas esgotados nem em vistas de deixarem de ser polêmicos. Se remontarmos à evolução do conceito de biosseguranca, descobriremos que a lógica de sua construção, que teve início na década de 1970, emergiu dos impactos da engenharia genética na sociedade. A partir daí o termo biossegurança, vem, ao longo dos anos, sofrendo alterações. Ainda na década de 1970, a Organização Mundial de Saúde (OMS) a definia como "práticas preventivas para o trabalho com agentes patogênicos para o homem", ou seja, neste momento o principal foco de atenção voltava-se para a saúde do trabalhador frente aos riscos biológicos no ambiente ocupacional. Já na década de 1980, a própria OMS (WHO, 1993) incorporou à sua definição os chamados riscos periféricos presentes em ambientes laboratoriais que trabalhavam com agentes patogênicos para o homem, como os riscos químicos, físicos, radioativos e ergonômicos.

Nos anos 1990, verificamos que a definição de biossegurança sofre mudanças significativas com a inclusão de temas como ética em pesquisa, meio ambiente, animais e processos envolvendo tecnologia de DNA recombinante em programas de biossegurança. Assim, surge outra definição que diz que "a biossegurança é o conjunto de ações voltadas para a prevenção, minimização ou eliminação de riscos inerentes às atividades de pesquisa, produção, ensino, desenvolvimento tecnológico e prestação de serviços, visando à saúde do homem, dos animais, a preservação do meio ambi- ente e a qualidade dos resultados" (TEIXEIRA \& VALLE, 1996). Este foco de atenção retorna ao ambiente ocupacional e amplia-se para a proteção ambiental e a qualidade (COSTA \& COSTA, 2002).

Neste contexto complexo de conceituações e da própria evolução do conceito de biosseguranca, verificamos que se trata de um conceito historicamente construído e que a possibilidade de um regime internacional de biosseguranca só começa a se forjar muito recentemente. Isto significa que importa menos a conclusão sobre sua inexistência e mais a atenção sobre seus impasses e possibilidades $^{6}$.

\section{IV.3. Teses concorrentes: EUA versus $U E$}

Inoue e Schleicher (2004) questionaram de que forma a teoria dos regimes pode, de fato, ajudar a compreender uma cooperação internacional de grande densidade no que se refere à biosseguranca, na medida em que o principal fator de um regime internacional, segundo Krasner (1989), é a convergência dos atores participantes em relação às normas, regras, princípios e procedimentos de tomada de decisão. Como seria possível compreender a existência de um regime no caso de biosseguranca, se os atores divergem em uma questão normativa antecedente à própria formação do regime?

Essa pergunta não está inserida só na reflexão sobre o papel da ciência ou da informação, mas antes disso, da própria concepção de ciência. Trata-se então de um excelente exemplo para a constatação da complexidade e inesgotabilidade da relação entre conhecimento e política internacional. Em outras palavras, além da oposição entre conhecimento e poder, há uma disputa entre a concepção de ciência - que antecede e que coincide ao mesmo tempo com a disputa pelo poder.

Inoue e Schleicher (2004) mencionam que a dificuldade do sucesso de um regime internacional de meio ambiente refere-se à existência de projetos distintos de "progresso": um 'cientificista' e outro 'precaucionário'. Para uma breve descrição dos parâmetros em disputa, podemos distin-

\footnotetext{
6 Sobre o debate ideológico internacional acerca de duas concepções de mundo envolvidas no diálogo sobre o tema, há uma boa ilustração da relação entre conhecimento e poder na análise de Cristina Inoue e Rafael Schleicher (2004).
} 
guir as posições a partir de uma análise metateórica que pressupõe um conflito entre cientificismo e precaução. Também para Robert Falkner, o cerne da negociação do Protocolo de Biossegurança foi uma disputa entre uma noção iluminista de progresso científico e o valor da precaução.

Para um bom desenvolvimento do tema, poderíamos acrescentar que este conflito é apenas mais um sintoma das profundas divergências sobre certa concepção de civilização entre duas potências que não disputam apenas um mercado econômico e financeiro internacional, mas autoridade ideológica, tradição e ética.

\section{CONCLUSÕES}

A relação entre o crescimento do Direito e da sociedade civil global coincide com o aumento da institucionalização internacional e com a busca da construção de um regime internacional de meio ambiente. No entanto, nem a concepção de regime internacional de Keohane parece suficiente para compreendermos o caso do regime de meio ambiente, na medida em que a cooperação pressuposta para a formação de um regime prevê ajustes mútuos (ainda que não se espere a superação total dos conflitos), no sentido de constituíremse regras comuns. Se regimes devem refletir expectativas convergentes entre os atores, podendo vir ou não a serem incorporadas em tratados ou organismos internacionais, é porque estes funcionam na constituição de soluções para problemas internacionais específicos. Seguindo esta concepção mínima de regimes, segundo Inoue e Schleicher (2004), é possível demonstrar que o conflito no seio da negociação do Protocolo de Biossegurança é mais do que um litígio comercial ou revela mais do que dificuldades em constituirse um regime internacional, pois demonstra diferentes visões de mundo. Os autores procuram apontar a insuficiência da teoria dos regimes internacionais para analisar o caso da formação do regime internacional de biossegurança, na medida em que há conflitos de percepção de mundo e de avaliação sobre o progresso e o papel da ciência entre os EUA e a UE.

Por tudo isso, não considero a valorização do papel das instituições uma forma de exclusão do papel do poder ou da "vontade de poder" exercida pelos estados e por atores não-estatais no ambiente internacional. Ao contrário, as instituições e os regimes são instrumentos racionais organiza- dos e, por meio deles, interesses podem ser perseguidos, e é por isso que importam. Por outro lado, a tese realista de que o papel da hegemonia nos regimes internacionais é absolutamente fundamental, tal como conferimos no caso do sucesso das instituições de Bretton Woods, também não se sustenta. Com afirma Young, sem negarmos os recursos assimétricos de pressão e influência, o fato é que a prevalência da vontade do poder hegemônico é exceção nos regimes internacionais. Isto se dá porque o controle dos recursos e capacidades tangíveis não se traduz com facilidade pela habilidade em determinar os outcomes coletivos (YOUNG, 1989a, p. 354; HART, 1976).

Uma importante vantagem dos Estados hegemônicos na garantia da supremacia no processo de poder decisório em instituições internacionais é que eles são capazes de agir simultaneamente em várias matérias e arenas, enquanto os Estados pequenos dependem de articular a formação de um grupo coeso para que ajam como frente de bloqueio em organizações em que o peso de suas opiniões, votos e participação é pequeno. Ainda assim, pode dar-se a prevalência dos interesses de um número maior de países com pesos e influências menos determinantes na constituição e sustentação de um regime internacional, como é o caso do regime penal internacional. Este é um exemplo de formação de regime em que pequenos Estados e principalmente atores da sociedade civil (indivíduos, associações, ONGs etc.) tiveram importância fundamental na criação e aprovação do Tribunal Penal Internacional (TOSTES, 2005).

A política internacional em um mundo globalizado não é um fenômeno unidimensional. Neste contexto, regimes e instituições representam o aumento e, em alguns casos, a fragmentação do campo de batalha para a luta pelo poder. Nesta arena atores não-estatais têm exercido um papel insuficiente e frágil, porém, ainda que frágil, podemos observar que o principal passaporte dos atores tem dependido de um forte engajamento em fóruns internacionais de debates, onde se enfrentam conflitos de interesse de alcance mundial. Foi assim no sistema penal internacional em que juristas e diplomatas, conhecedores do direito internacional e das conseqüências da adoção de regras de cessão de soberania, por exemplo, tiveram um papel fundamental no esclarecimento 
e convencimento dos atores estatais envolvidos no regime. Em outras palavras, apesar de ser um exemplo de fracasso (ou seja, negativo e não positivo), para se verificar a relação entre direito internacional, sociedade civil e regimes internacionais (se considerarmos a constituição dos regimes como objetivo final da equação), o regime sobre meio ambiente é o melhor exemplo para verificarmos que no contexto complexo da formação de regimes existem papéis fundamentais reservados ao debate de idéias, informação e ciência.

Neste mesmo cenário, visto de outra forma, funções importantes podem ser exercidas pela sociedade civil global que apenas diretamente não afetam outcomes políticos como o da divulgação de informações e da publicização de valores. Além disso, especialmente no caso do debate sobre diversidade biológica e certificação dos recursos genéticos, discussões da $8^{\text {a }}$ Conferência das Partes (COP-8), da Convenção sobre Diversidade Biológica das Nações Unidas (CDB), foram possíveis graças à participação e pressão de grupos interessados em defender a importância da expertise dos povos locais, detentores de um conhecimento tradicional insubstituível (que inclui conhecimentos, informações e práticas) sobre a biodiversidade. Além disso, o caráter transfronteiriço do chamado conhecimento tradicional faz com que a perspectiva interna dos atores envolvidos, tanto nas avarias quanto na eventual distribuição de benefícios de um sistema de regulação da exploração da biodiversidade, seja inseparável das ações em defesa da preservação e sobrevivência de grupos locais (etnias indígenas e nativos, tais como caiçaras, extrativistas e ribeirinhos) das regiões onde são perpetuados os conhecimentos tradicionais como, por exemplo, o uso medicinal de animais (etnozoologia ou zooterapia popular) e plantas ou os conhecimentos práticos das quebradeiras de coco.

Segundo Goldstein e Keohane (1993), três idéias constam nas relações internacionais: world views (que se entrelaça com a concepção de identidade, evocada por emoções e lealdades profundas); principal beliefs (gera e é gerada por convicções sobre justo/injusto; certo/errado) e causal beliefs (crença na relação causa-efeito que deriva de um consenso compartilhado por autoridades reconhecidas). A principal contribuição teórica que vem suportando diretamente esta perspectiva do impacto das causal beliefs tem sido a do construtivismo (GOLDSTEIN \& KEOHANE, 1993), pois as causal beliefs impactam a expertise baseada na construção de comunidades epistêmicas ou networks transnacionais (HAAS, 1992). Assim, nesses campos, a pesquisa empírica só pode visar relatar o papel exercido pelas causal beliefs na construção de consensos e sua influência no processo de tomada de decisão por aqueles que detêm tal poder.

Se isto estiver certo, é verdade que atores nãoestatais ainda não mudaram as regras de competição e uso da força nas relações internacionais nem exercem poderes deliberativos em organizações internacionais, porém eles passam a importar cada vez mais em um cenário em que o Direito é valorizado e sempre que informação e divulgação da informação, bem como conhecimentos tradicionais, ciência e tecnologia, também importarem nas relações de poder. Lembrando que, segundo Keck e Sikkink (1999), historicamente, em temas como direitos humanos ou abolição da escravatura, o papel das networks não foi em vão. A colocação de temas em agenda e a denúncia sobre os abusos - seja no campo dos direitos humanos, seja no campo do desenvolvimento sustentável - é um importante instrumento de influência política capaz de gerar, a médio e longo prazo, mudanças de percepção, de crenças, influência no aparecimento de novas idéias e pesquisas, consciência dos problemas e, em última instância, mudança de comportamento dos atores envolvidos e até mesmo de governos.

Ana Paula Tostes (aptostes@usp.br) é Doutora em Ciência Política pelo Instituto Universitário de Pesquisas do Rio de Janeiro (Iuperj), Professora no Departamento de Ciência Política da Universidade de São Paulo (USP) e pesquisadora da mesma instituição. 


\section{REFERÊNCIAS BIBLIOGRÁFICAS}

ANHEIER, H.; GLASIUS, M. \& KALDOR M. (eds.). 2001. Global Civil Society. Oxford : Oxford University.

ANDRESEN, S.; SKODVIN, T.; UNDERDAL, A. \& WETTSTAD, J. 2000. Science and Politics in International Environmental Regimes : Between Integrity and Involvement. Manchester : Manchester University.

ANDRESEN, S. \& OSTRENG, W. 1989. International Resource Management : the Role of Science and Politics. New York : Belhaven.

BELLANY, I. 1997. The Environment in World Politics : Exploring the Limits. Cheltenham : E. Elgar.

COSTA, M. A. F. 1996. Biossegurança : segurança química básica para ambientes hospitalares e biotecnológicos. São Paulo : Santos.

COSTA, M. A. F. \& COSTA, M. F. B. 2002. Biossegurança : elo estratégico de SST. Revista CIPA, Rio de Janeiro, n. 253, jan.

DIMITROV, R. S. 2006. Science \& International Environmental Policy: Regimes and Nonregimes in Global Governance. Oxford : Rowman \& Littlefield.

FALKNER, S. R. 2000. Regulation Biotech Trade : The Cartagena Protocol on Biosafety. International Affairs, Peterborough, v. 76, n.2.

FISCHER, F. 2000. Citizens, Experts, and the Environment : The Politics of Local Knowledge. Durham, North Carol. : Duke University.

GLASIUS, M.; KALDOR, M. \& ANHEIER, H. (eds.). 2002. Global Civil Society. Oxford : Oxford University.

GOLDSTEIN, J. \& KEOHANE, R. (eds.). 1993. Ideas and Foreign Policy. Ithaca : Cornell University.

HAAS, P. M.; KEOHANE, R. O. \& LEVY, M. A. 1993. Institutions for the Earth: Sources of Effective International Environmental Protection. Cambridge : MIT.

HAAS, P. 1989. Do Regimes Matter? Epistemic Communities and Mediterranean Pollution Control. International Organization, Cheltenham, v. 43, n. 3, p. 377-403.
1992. Introduction : Epistemic Communities and International Policy Coordination. International Organization, Cheltenham, v. 46, n. 1, p. 1-35, Winter.

. (ed.). 1997. Knowledge, Power, and international Policy Coordination. Columbia : University of South Carolina.

HART, J. 1976. Three Approaches to the Measurement of Power in International Relations. International Organization, Cheltenham, v. 30, p. 299-305.

HURRELL, A. 1995. International Political Theory and the Global Environment. In : BOOT, K. \& SMITH, S. (eds.). International Relations Theory Today. Pennsylvania : Penn State University.

INOUE, C. \& SCHLEICHER, R. 2004. Conhecimento científico e formação de regimes internacionais ambientais : o caso do regime de biossegurança. Cena Internacional, Brasília, $\mathrm{n}$. 6, p. 13-35.

INSERM. 1991. Les risques biologiques en laboratoire de recherche. Paris : Institut Pasteur.

JASANOFF, S. 1990. The Fifth Branch : Science Advisers as Policymakers. Cambridge, Mass. : Harvard University.

KECK, M. E. \& SIKKINK, K. 1998. Activists beyond Borders : Advocacy Networks in International Politics. Ithaca : Cornell University.

KEOHANE, R. \& MILNER, H. 1996. Internationalization and Domestic Politics. Cambridge : Cambridge University.

KEOHANE, R. 1983. The Demand for International Regimes. In : KRASNER, S. D. (ed.). International Regimes. New York : Cornell University.

. 1988. Después de la hegemonía : cooperación y discordia en la política económica mundial. Buenos Aires : Grupo Editor Latinoamericano.

1993. Instituciones Internacionales y poder estatal. Buenos Aires : Grupo Editor Latinoamericano. 
KRASNER, S. D. (ed.). 1989. International Regimes. Ithaca : Cornell University.

KRATOCHWILL, F. V. 1989. Rules, Norms, and Decisions : On the Conditions of Practical and Legal Reasoning in International Relations and Domestic Affairs. Cambridge : Cambridge University.

LAFER, C. \& FONSECA JR., G. 1994. Questões para a diplomacia no contexto internacional das polaridades indefinidas. In : FONSECA JR., G. \& CASTRO, S. N. (orgs.). Temas de politica externa brasileira II. São Paulo : Paz e Terra.

LIPSCHUTZ, R. D. 2004. Global Environment Politics : Power, Perspectives, and Practice. Washington, D. C. : CQ.

LITFIN, K. T. 1994. Ozone Discourses : Science and Politics in Global Environmental Cooperation. New York : Columbia University.

1995. Framing Science : Precautionary Discourse and the Ozone Treaties. Millennium: Journal of International Studies, London, n. 24, p. 251-77.

MITCHEL, R. B. 1994. Regimes Design Matters : International Oil Pollution and Treaty Compliance. International Organization, Cheltenham, v. 48, n. 3, p. 425-458.

NYE JR., J. S. 2002. Compreender os conflitos internacionais. Lisboa: Gradiva.

O'RIORDAN, T. \& JAGER, J. 1996. Politics of Climate Change : an European Perspective. London : Routledge.

PARSON, E. A. 2003. Protecting the Ozone Layer: Science and Strategy. Oxford: Oxford University.

PATERSON，M.; HUMPHREYS，D. \& PETTIFORD, L. 2003. Conceptualizing Global Environmental Governance : From Interstate Regimes to Counter-Hegemonic Struggles. Global Environmental Politics, Boulder, v. 3, p. 1-10, May.

PORTER, G. \& BROWN, J. 1996. Global Environmental Politics. Boulder : Westview.

SODEN, D. L. \& STEEL, B. S. 1999. Handbook of Global Environmental Policy and Administration. New York : M. Dekker.
SOROOS, M. 1997. The Endangered Atmosphe$r e$ : Preserving a Global Commons. Columbia : University of South Carolina.

STEIN, A. 1990. Why Nations Cooperative : Circunstance and Choice in International Relations. Ithaca : Cornell University.

STERN, P.; YOUNG, O. \& DRUCKMAN, D. (eds.). 1992. Global Environmental Change: Understanding the Human Dimensions. Washington, D. C. : National Academy.

TEIXEIRA, P. \& VALLE, S. 1996. Biossegurança : uma abordagem multidisciplinar. Rio de Janeiro : Fundação Oswaldo Cruz.

TOSTES, A. P. 2005. O indivíduo, o Direito e a política internacional : puxando o fio de Ariadne. In : TOSTES, A. P. \& VITA, A. (orgs.). Justiça e processos democráticos transnacionais. São Paulo : Humanitas.

VIOLA, E. 1997. The Environmental Movement in Brazil : Institutionalization, Sustainable Development and Crisis of Governance since 1987. In : MACDONALD, G.; NIELSON, D. \& STERN, M. (eds.). Latin American Environmental Policy in International Perspective. Boulder: Westview.

1998. Globalization, Environmentalism and new Transnational Social Forces. In : CHUNG, C. \& GILLESPIE, B. (eds.). Globalization and the Environment. Paris : Organization for Economic Co-operation and Development.

WALTZ, K. N. 2002. Teoria das Relações Internacionais. Lisboa : Gradiva.

2000. Structural Realism after the Cold War. International Security, Cheltenham, v. 25, n. 1, p. 5-41, Summer.

WHO. 1993. Laboratory Biosafety Manual. $2^{\text {nd }}$ ed. Geneve : World Health Organization.

YOUNG, O. R. 1989a. International Cooperation : Building Regimes for Natural Resources and the Environment. Ithaca : Cornell University.

1989b. The Politics of International Regime Formation : Managing Natural Resources and the Environmental. International Organization, Cheltenham, v. 43, p. 349-375, Summer. 
1999. The Effectiveness of International Environmental Regimes : Causal Connections and Behavioral Mechanisms. Cambridge, Mass. : MIT.

1991. Political Leadership and Regimes Formation : On the Development of Institutions in International Society. International Organization, Cheltenham, n. 45, p. 281-308, Summer.
YOUNG, O. R. \& OSHERENKO (eds.). 1993. Polar Politics : Creating International Environmental Regimes. Ithaca : Cornell University.

ZÜRN, M. 1998. The Rise of International Environmental Politics. A Review of Current Research. World Politics, Washington, D. C., v. 50, p. $617-49$. 